\title{
Inhibition of CYP2S1 mediated metabolism of anticancer prodrug AQ4N by liarozole
}

\author{
Naveen K. M. Singh ${ }^{1}$, Shawn R. White ${ }^{2}$, Sudhakar Kalagara ${ }^{3}$, Samuel Kadavakollu ${ }^{1 *}$ \\ ${ }^{1}$ Department of Chemistry and Biochemistry, New Mexico State University, Las Cruces, NM, USA. \\ ${ }^{2}$ Department of Chemistry, Western New Mexico University, Silver City, NM, USA. ${ }^{3}$ Department of Chemistry, University of Texas at El Paso, TX, USA.
}

\begin{tabular}{l} 
ARTICLE INFO \\
\hline Article history: \\
Received on: $21 / 04 / 2016$ \\
Accepted on: $30 / 06 / 2016$ \\
Available online: $27 / 02 / 2017$ \\
\hline Key words: \\
CYP2S1, Toxicity, Inhibition \\
Activity, AQ4N, AQ4, \\
Banoxantrone and Liarozole.
\end{tabular}

\begin{abstract}
CYP2S1 is an orphan Cytochrome P450 whose expression is elevated in numerous epithelial derived cancers; however, little is known about CYP2S1 inhibitors. Our results indicate that liarozole acts as an effective inhibitor of CYP2S1, and decreases the turnover of the prodrugAQ4N to its active metabolites AQ4M and AQ4. Our studies also found that the active drug AQ4 is found only in the perinuclear location, whereas the prodrug AQ4N is located in the cytoplasm. In addition, we showed that AQ4N is non-geno/cytotoxic whereas the bioreduced metabolite AQ4 is both genotoxic and cytotoxic. Finally, we observed that CYP2S1 metabolizes AQ4N under anoxic conditions and that increasing the CYP2S1 concentration leads to more AQ4N turnover. The important enzymatic role of CYPS2 1 with regard to the metabolism of the anticancer prodrug AQ4N into AQ4 was confirmed.
\end{abstract}

\section{INTRODUCTION}

Cytochrome P450 (CYPs) constitute a large superfamily of enzymes that are haem-thiolate proteins with ubiquitous expression and distribution in diverse life forms including bacteria, fungi, plants and animals (Nelson et al., 1999). CYPs play an important role in carcinogen and anticancer drug biotransformation (Tang et al., 2015). Within cells, CYPs are localized to the endoplasmic reticulum (ER) and mitochondria (Szczesna-Skorupa et al., 2008). In total, 58 human cytochrome P450s (CYPs) have been identified to date. Most CYPs have been well characterized, and biological substrates have been identified for nearly $75 \%$ of all known CYPs. However there remains $25 \%$ of CYPs called "orphan P450s" which little physiological function has clearly been identified. CYP2S1 is a gene coding for the Cytochrome P450 2S1 protein, which has been shown to metabolize AQ4N, an anticancer prodrug, under anoxic conditions (Xiao et al., 2011, Nishida et al., 2010). The epoxygenase activity of CYP2S 1 is inhibited in vitro by miconazole and liarozole, an inhibitor of CYP26 and CYP2S1 (Fromel et al., 2013). Several ongoing studies have

\footnotetext{
* Corresponding Author

Samuel Kadavakollu, Department of Chemistry, Western New Mexico University, Silver City, NM, USA. Email:samuelk@wnmu.edu
}

identified endogenous and exogenous substrates of CYP2S1. However, very few studies have examined the role of inhibitors on CYP2S1 mediated metabolism of substrates like AQ4N. We therefore examined the role of liarozole, a known inhibitor of CYP enzymes in CYP2S1 mediated metabolism of AQ4N. Banoxantrone $(\mathrm{AQ} 4 \mathrm{~N})$ is an anticancer prodrug that requires both a hypoxic environment and metabolic activation to generate the ultimate toxicant, a topoisomerase II inhibitor, AQ4. Heterologous CYP2S1 expression studies have revealed that AQ4N is a substrate for CYP2S1 (Nishida et al., 2010), and that CYP2S1 metabolizes non-cytotoxic AQ4N to AQ4M and cytotoxic AQ4. While there have been numerous studies conducted to identify the substrates of CYP2S1, there is very little information on its inhibitors. Liarozole is an imidazole-containing compound that inhibits the cytochrome P-450-dependent metabolism of ATRA in hamster liver microsomes (Van Wauwe et al., 1992). Previous studies have shown that liarozole inhibits human epidermal retinoic acid 4hydroxylase activities (Kang et al., 1996). Liarozole acts as a blocker of retinoic acid metabolism (retinoic acid metabolism blocking agent, RAMBA) and has been shown to inhibit CYP26A1 (Nelson et al., 2013). It is a known Cytochrome P450 inhibitor, which inhibits several cytochrome P450 enzymes including aromatase (CYP19), a key enzyme in the biosynthesis of estrogens and retinoic acid 4-hydroxylase (CYP26S), responsible for ATRA metabolism (PavezLorie et al., 2009). 
Liarozole also displays antitumor activity against androgen-dependent and independent rat prostate carcinomas (Smets et al., 1995). A hypoxic environment is exhibited by solid tumors due to poor vascularization resulting from the rapid growth of tumors. Tirapazamine (Brown et al., 1999), mitomycin (Tomasz 1995), NLCQ-1 (Papadopoulou and Bloomer 2003), KS119 (Seow et al., 2005) and AQ4N (Patterson et al., 2002, Lalani et al., 2007) are a few anticancer agents that are selectively activated in an hypoxic environment (Nishida et al., 2010). AQ4 itself is not suitable as an anticancer drug because it is highly toxic to normal cells (Nishida et al., 2010) whereas AQ4N has negligible topoisomerase inhibitory activity (Patterson et al., 1994, Smith et al., 1997). When AQ4Nreaches hypoxic tumor cells the drug is selectively converted into its active cytotoxic form AQ4. The active form of the drug AQ4 has been shown to be a potent topoisomerase II inhibitor and DNA intercalator (Patterson et al., 2000). This work focuses on the role of the liarozole inhibitor on CYP2S1 and its subsequent effect on metabolism of AQ4N.

\section{MATERIALS AND METHODS}

\section{Cell Lines and Reagents}

A549 and BEAS2B were obtained from ATCC. A549s were grown in DMEM (Invitrogen, Cat. No. 31053-036) with 10\% FBS media (Invitrogen, Cat. No. 16000-044) and BEAS2B were grown in LHC9 media (Invitrogen, Cat. No.12680-013). The cell lines were kept in $37^{\circ} \mathrm{C}$ incubator with $5 \% \mathrm{CO}_{2}$ conditions. The media was changed every other day until the cells were $80-90 \%$ confluent, and then the cells were split using Trypsin $0.25 \%$ EDTA (Invitrogen, Cat. No. 25200-056) for A549s and TrpLE for Beas2Bs (Invitrogen, Cat. No. 12604-021). Phosphate buffer Saline (PBS) was used to wash the cells (Invitrogen, Cat. No. 10010-023).

\section{Cell Genotoxicity Assays}

Genotoxicity (DNA damage) in BEAS2B was evaluated using Trevigen Comet Assay ${ }^{\mathrm{TM}}$ kit (Trevigen Inc., Gaithersburg, MD, Catalog No. \# 4250-050-K) according to the manufacturers protocol. BEAS2B was plated in six well plates at a density of $\sim 1.2 \mathrm{X} 10^{6}$ cells/mlfor treatment with AQ4N, AQ4 or Mitoxantrone. Three different concentrations of drug 1, 10 and $100 \mu \mathrm{M}$, were used. BEAS2B adherent cells were trypsinized and cells were resuspended in ice cold PBS to a concentration of $1 \mathrm{X}$ $10^{5} \mathrm{cells} / \mathrm{ml}$. The cells were combined with low melting agarose (at $\left.42^{\circ} \mathrm{C}\right)$ at a ratio of $1: 10(\mathrm{v} / \mathrm{v})$ and immediately pipetted $(50 \mu \mathrm{l})$ onto CometSlide ${ }^{\mathrm{TM}}$. The slides were incubated in the dark at $4{ }^{\circ} \mathrm{C}$ for $10 \mathrm{~min}$ and them immersed in $4^{\circ} \mathrm{C}$ Lysis Solution for $60 \mathrm{~min}$. The slides were then transferred to a beaker with Alkaline Unwinding Solution for $20 \mathrm{~min}$ at room temperature or $1 \mathrm{hr}$ at $4^{\circ} \mathrm{C}$, in the dark for denaturation. Approximately $850 \mathrm{ml}$ of prechilled Alkaline Electrophoresis Solution was added to Comet Assay® ES unit. Then,the slides were subjected to electrophoresis at $1 \mathrm{~V} / \mathrm{cm}, 300 \mathrm{~mA}$ for $40 \mathrm{~min}$ in the dark. After electrophoresis, the slides were removed and gently drained of excess electrophoresis solution, and washed by immersing twice in neutralization buffer for $5 \mathrm{~min}$ each and in $70 \%$ ethanol for $5 \mathrm{~min}$ followed by air-drying at room temperature for $10-15 \mathrm{~min}$. $100 \mu \mathrm{l}$ of diluted $\mathrm{SYBR}^{\circledR}$ Gold was placed onto each circle of dried agarose and stained for $30 \mathrm{~min}$ at room temperature in the dark. The slides were allowed to dry completely at $37^{\circ} \mathrm{C}$ and analyzed using View slides by epifluorescence microscopy using Nikon e600 microscope using fluorescein filter with excitation/emission at $496 \mathrm{~nm} / 522 \mathrm{~nm}$. The relative DNA damage (Genotoxicity) was analyzed using olive tail moment, a product of tail length and the fraction of total DNA in the tail. Prism statistical software (Graphpad Prism 5.0) was used to graph the results obtained.

\section{Cell Cytotoxicity Assays}

The cell cytotoxicity assays were performed using AlamarBlue $^{\circledR}$ cell viability reagent (Life Technologies, Cat. No.: DAL1100) according to the manufacturer's protocol. BEAS-2B cells were plated at 2,000 to 4,000 cells per well, in triplicates, of at least four per treatment or genotype, in a 96 well plate. The cell numbers for plating were calculated using the hemocytometer after trypsinizing BEAS2B cells in a T-75 flask grown to $90 \%$ confluency. The cells were allowed to grow overnight at $5 \% \mathrm{CO}_{2}$ at $37^{\circ} \mathrm{C}$

The following day media with three different concentrations $(1,10$ or $100 \mu \mathrm{M})$ of the drug (AQ4N, AQ4 or Mitoxantrone) was added to three different plates each representing one of the drug treatments. Drug preparations were done in DMSO as described elsewhere in experimental procedures. For negative controls, DMSO and untreated media were used.For the positive control, fully reduced alamarBlue $\AA$ prepared by autoclaving media with $10 \%$ alamarBlue ${ }^{\circledR}$ was used. Finally, media without cells was used as a blank to establish the background. The 96 well plates were now placed in a hypoxic chamber for $24 \mathrm{hrs}$ at $1 \% \mathrm{O}_{2}, 5 \% \mathrm{CO}_{2} / 37^{\circ} \mathrm{C}$, and control samples were placed in a $5 \% \quad \mathrm{CO}_{2}$ incubator at $37^{\circ} \mathrm{C}$. After $24 \mathrm{hr}$, alamarBlue $^{\circledR}$ was added to a final concentration of $10 \%$, after which the cells were incubated for four more hours at previously described conditions.

The fluorescence measurements of the plates were recorded with the following parameters: excitation wavelength at 530-560nm and emission wavelength at $590 \mathrm{~nm}$. Percentage reduction of alamarBlue ${ }^{\circledR}$ was calculated and these values were used to compare cells. All data points were normalized to blank media wells (alamarBlue ${ }^{\circledR}$ background fluorescence levels). The experiments were conducted at least three times under identical conditions.

Fluorescence measurements were analyzed using Prism statistical software (Graphpad Prism 5.0), analyzing linear cytotoxicity levels at different concentrations of the drug.

\section{Isolation of CYP2S1 Microsomal Fractions}

CYP2S1 overexpressing microsomes were isolated according to methods as described by Fromel et al., (2013), with some modifications to the protocol. BEAS2B stable cell lines 
overexpressing CYP2S1 ( $\sim$ fold) were grown until approximately $90 \%$ confluent in $75-\mathrm{ml}$ flasks and harvested by trypsinization. Following centrifugation at $5000 \mathrm{rpm}$ for $10 \mathrm{~min}$, the cell pellet was collected. Microsomal fractions were prepared by repeat centrifugation. The cell pellet was homogenized in 3volumes of $\mathrm{KCl}$ (50mM, pH 7.4) containing EDTA (1mM) and $\mathrm{MgCl}_{2}(3 \mathrm{mM})$ and centrifuged at $13000 \mathrm{rpm}$ for $10 \mathrm{~min}$ at room temperature. Following centrifugation at $41000 \mathrm{~g}$ for $30 \mathrm{~min}$ at $4^{\circ} \mathrm{C}$, microsomes were resuspended in $\mathrm{KCl}$ containing $0.25 \mathrm{M}$ sucrose. Microsomal preparations $(0.25 \mathrm{mg})$ were then pre-incubated with AQ4N/AQ4 for $5 \mathrm{~min}$.

The reaction wasinitiated by the addition of an NADPH regenerating system at a final concentration. of $1.2 \mathrm{mM}$ (Stock $100 \mathrm{mM}$ ). Reactions were carried out in a shaking water bath for 30 min and terminated by the addition of methanol $(1 \mathrm{ml})$. Samples were vortexed for $2 \mathrm{~min}$ and the upper organic phase removed into a clean HPLC vial following centrifugation at 3500rpm for $15 \mathrm{~min}$ at $4{ }^{\circ} \mathrm{C}$.

\section{Drug Incubations}

$400 \mu \mathrm{g}$ of microsomal protein was preincubated for $5 \mathrm{~min}$ at $37^{\circ} \mathrm{C}$ under anaerobic conditions in $0.1 \mathrm{M}$ sodium/potassium phosphate buffer ( $\mathrm{pH}$ 7.6) containing $5 \mathrm{mM}$ NADPH. Metabolic reactions were initiated with the addition of $A Q 4 N$ to a final concentration of $100 \mu \mathrm{M}$. The total reaction volume was $250 \mu \mathrm{l}$. After $60 \mathrm{~min}$, reactions were terminated by the addition of $50 \%$ $\mathrm{v} / \mathrm{v}$ acetonitrile $(250 \mu \mathrm{l})$ and deproteinized by centrifugation $(12000 \mathrm{~g})$ for $5 \mathrm{~min}$. Control reactions were performed in the absence of microsomes or NADPH, and under aerobic conditions.

\section{AQ4N Assays}

Chromatographic analysis of AQ4N using High Performance Liquid Chromatography (HPLC) was done as described by Loadman et al., (2001). A Hichrom RPB (25-cm $\times$ 4.6-mm i.d.) column (Hichrom Ltd., Reading, UK) was used for the separation. A Waters 996 Photodiode Array Detector $\left(\lambda_{1}=240\right.$ $\mathrm{nm}, \lambda_{2}=612 \mathrm{~nm}$ ) with Millenium Software (Waters Ltd., Watford, UK) was used for spectral analysis of the peaks of interest. The flow rate was set at $1.2 \mathrm{ml} / \mathrm{min}$ with Waters model 510 HPLC pump and samples introduced via Waters 717 plus Autosampler. The mobile phase used was $78 \%$ ammonium formate buffer $(0.05 \mathrm{M}) / 22 \%$ acetonitrile with final $\mathrm{pH}$ adjusted to 3.6 with formic acid.

\section{Liarozole Inhibition Studies}

5-[(3-Chlorophenyl)- $\quad$ 1H-imidazol-1-ylmethyl]-1Hbenzimidazole hydrochloride (liarozole) (Tocris biosciences, Cat. No. 2705) was used for inhibition studies. A stock concentration of $50 \mathrm{mM}$ was prepared by diluting in DMSO. $20 \mu \mathrm{M}$ CYP2S1 protein was pre-incubated with $50 \mu \mathrm{M}$ Liarozole for $1 \mathrm{hr}$ at room temperature.

Nitrogen gas was bubbled through the sample. The samples were incubated for $5 \mathrm{~min}$ at $37{ }^{\circ} \mathrm{C}$ under anaerobic conditions in $0.1 \mathrm{M}$ sodium/potassium phosphate buffer $(\mathrm{pH} 7.6)$ containing $5 \mathrm{mM}$ NADPH and $\mathrm{P} 450$ reductase (Life Technologies, Cat. No. P2309). Metabolic reactions were initiated with the addition of AQ4N to a final concentration of $100 \mu \mathrm{M}$. The total reaction volume was $250 \mu \mathrm{l}$. After $60 \mathrm{~min}$, reactions were terminated by the addition of $50 \% \mathrm{v} / \mathrm{v}$ acetonitrile $(250 \mu \mathrm{l})$ and deproteinized by centrifugation $(12000 \mathrm{~g}$ ) for $5 \mathrm{~min}$. Control reactions were performed in the absence of liarozole. The control and test samples were run on HPLC as described earlier. The AQ4N, AQ4M and AQ4 peak areas obtained from HPLC were graphed using MS-Excel and Prism statistical software (Graphpad Prism 5.0) to compare the relative turnover of AQ4N in the presence and absence of liarozole.

\section{RESULTS and DISCUSSION}

\section{AQ4, the active drug, is found in the perinuclear location whereas the prodrug AQ4N is located in the cytoplasm.}

To understand the bioreduction of AQ4N metabolism, we performed fluorescence imaging studies of BEAS-2B and A549 cell lines.AQ4N undergoes two-electron reduction to get metabolized into the cytotoxic AQ4 (Fig.1A), which acts as a topoisomerase II inhibitor. Liarozole (Fig. 1B), a known CYP inhibitor, was used to inhibit CYP2S1 mediated metabolism of AQ4N to AQ4.

In order to access the location of the prodrug AQ4N and the active form of the drug AQ4, fluorescence images of BEAS2B and A549 (Fig. 2) treated with AQ4N and AQ4 were taken using epifluorescence microscopy. Our results indicate that the prodrug AQ4N (Fig.2: A to F) is located in the cytoplasm in both BEAS2B and A549 cell lines and did not penetrate into the nucleus, even after 60 minutes of incubation.

The active drug AQ4; however, is found in the perinucleur location (Fig.2: G to L). Our results are consistent with the function of the active drug AQ4 that acts by intercalating DNA and inhibiting topoisomerase II.

\section{The prodrug AQ4N is non-geno/cytotoxic whereas the bioreduced metabolite AQ4 (active form) is both genotoxic and cytotoxic}

The differences in genotoxicity and cytotoxicity of AQ4N and AQ4 have been confirmed using alkaline comet assay to detect DNA damage and alamar Blue assays for the cytotoxicity studies. BEAS2Bs treated with the control AQ4N, an inactive prodrug, did neither show any genotoxicity nor cytotoxicity whereas the active form of the drug AQ4 was both genotoxic as well as cytotoxic to the cells. There was also a dose dependent increase in the genotoxicity with the increasing levels of AQ4; however, AQ4N did not show any toxicity even with the increasing dosage (Fig. 3A). The results obtained from the genotoxicity studies are in agreement with the results obtained from cytotoxic studies. Our cytotoxicity studies of AQ4N and AQ4 indicate that the active form of the drug AQ4 is cytotoxic and the toxicity is dose-dependent, whereas the prodrug AQ4N is noncytotoxic even with increasing concentrations of the drug (Fig. 3B). 


\section{A}

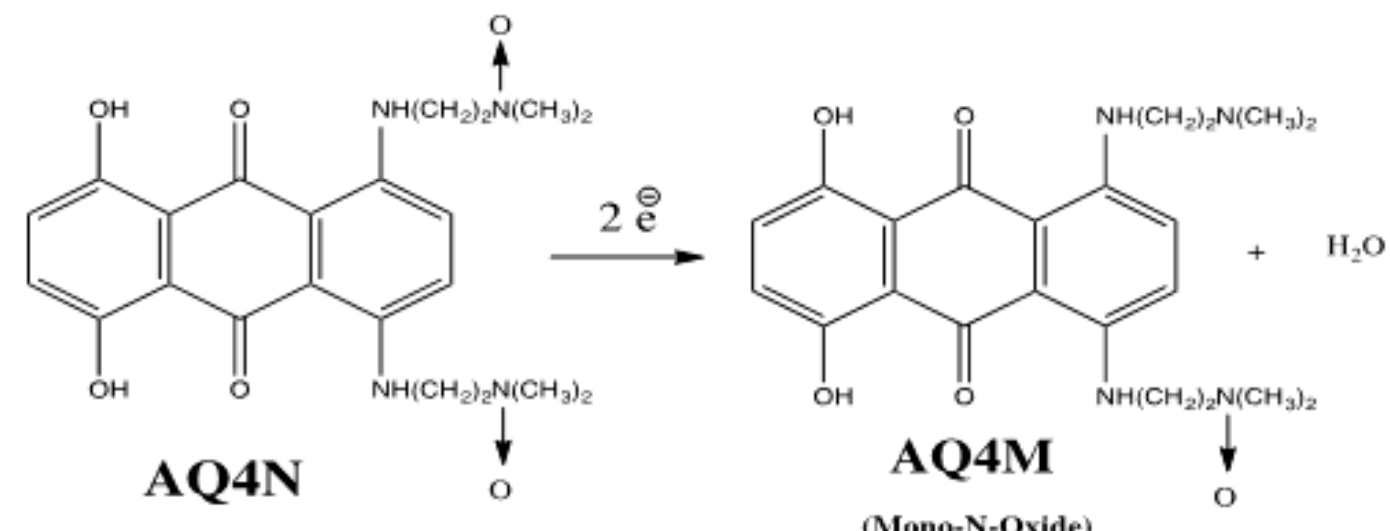

(Mono-N-Oxide)

\section{$2 \stackrel{\ominus}{\mathrm{e}}$}<smiles>CCCCCNc1ccc(NCCCC)c2c1C(=O)c1c(O)ccc(O)c1C2=O</smiles>

\section{AQ4}

B<smiles>Clc1cccc(C(c2ccc3nc[nH]c3c2)n2ccnc2)c1</smiles>

Liarozole

Fig. 1: AQ4N, AQ4M, AQ4 and liarozole(A). Bioreduction of AQ4N into its metabolites AQ4M and AQ4. AQ4N undergoes two-electron reduction to get metabolized into the cytotoxic AQ4. (B). Structure of liarozole.

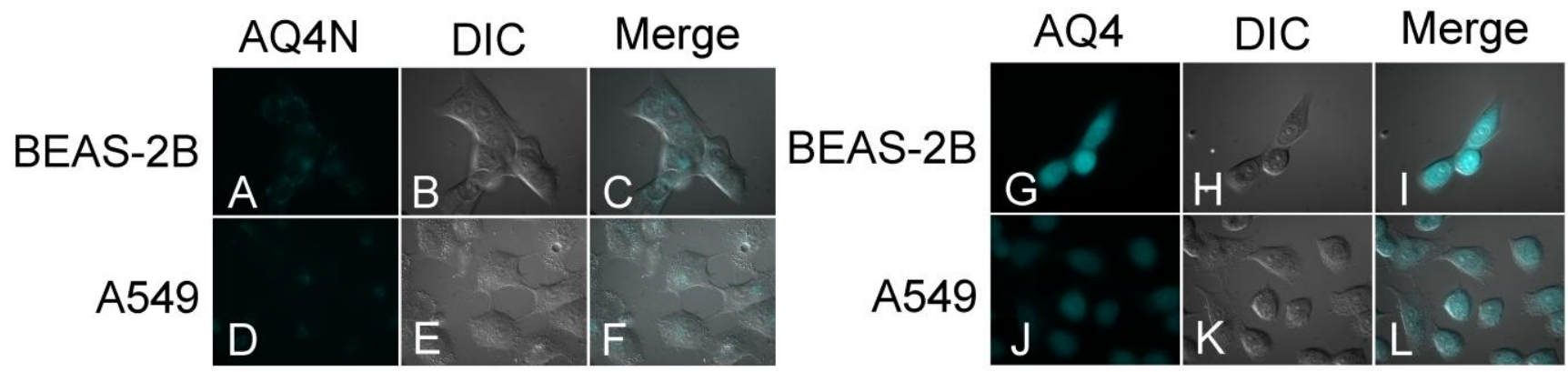

Fig. 2: Fluorescence images of BEAS-2B and A549 treated with AQ4N and AQ4. Cells were grown in glass bottom 35 -mm dishes and treated with $50 \mu \mathrm{M}$ of AQ4N or AQ4, incubated for $60 \mathrm{~min}$. and were scanned with appropriate excitation (wavelength, $633 \mathrm{~nm}$ ) and emission (650 nm LP) filters using Zeiss epifluorescene microscope. Differential Interference Contrast (DIC) shows unstained transparent samples. It can be seen from Fig. A-F that the prodrug AQ4N is located in the cytoplasm in both BEAS2B and A549 cell lines and did not penetrate into the nucleus, even after 60 minutes of incubation. The active drug AQ4; however, is located in perinucleur location (Fig. G-L). 

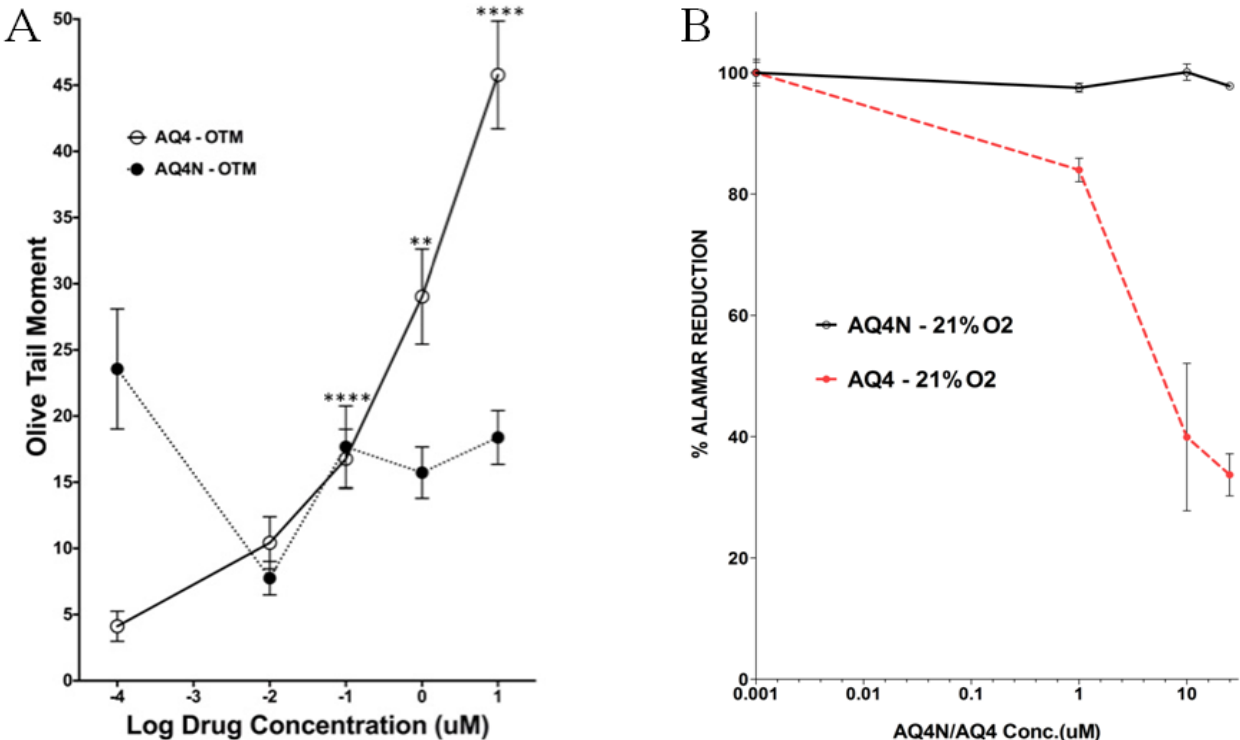

Fig. 3: AQ4N is non-genotoxicand non-cytotoxic whereas the active drug is both genotoxic as well as cytotoxic to BEAS2B under normoxic conditions. (A). Genotoxicity of AQ4N and AQ4 in BEAS2BS at normoxic conditions using alkaline comet assay. Statistical significance was determined using a Student's $t$ test. Data are represented as mean \pm S.D, $*^{* * *}, p \leq 0.0001, * *, p \leq 0.01$. AQ4N does not show any DNA damage, whereas AQ4 shows genotoxicity. (B). Cytotoxicity of AQ4N and AQ4 at normoxic conditions in BEAS2B represented by \% Alamar reduction. AQ4N is not cytotoxic with increasing dose, whereas AQ4 is cytotoxic to the cells.

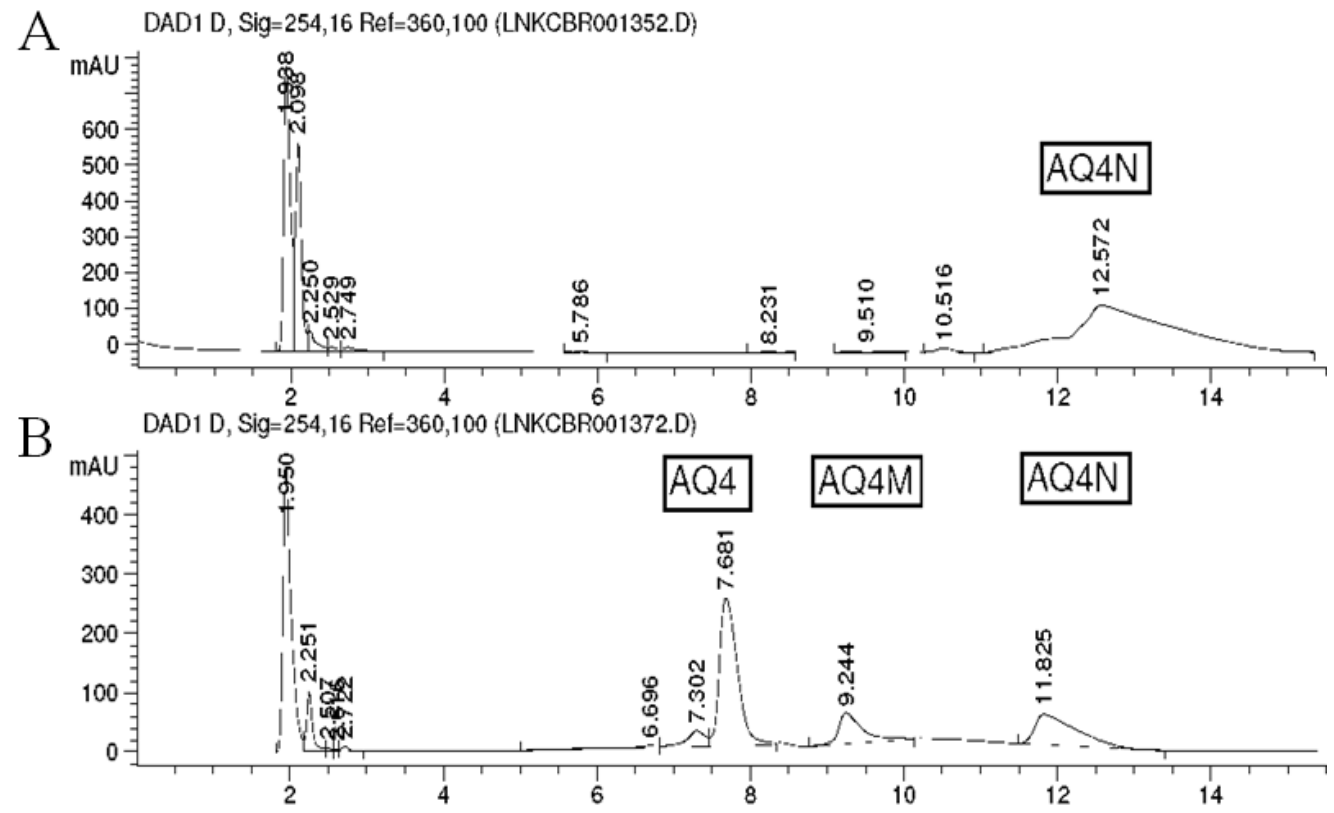

Fig. 4: HPLC analysis of bioreduction of AQ4N by CYP2S1 under anoxic conditions. (A). Representative HPLC chromatogram of control reaction with AQ4N treated with PBS instead of CYP2S1 showing AQ4N not metabolized into AQ4M or AQ4. (B) Representative HPLC chromatogram of AQ4N metabolism using CYP2S1, into AQ4M and AQ4 under hypoxic conditions. X-axis represents retention time in min, and the $\mathrm{Y}$-axis is absorbance in mAU.

\section{CYP2S1 metabolizes AQ4N under anoxic conditions and increasing CYP2S1 concentration leads to more AQ4N turnover.}

Anticancer prodrugs can only be activated by bioreduction into the cytotoxic compound under hypoxic environment. Hypoxia enables the reductive activation of anticancer prodrugs that cannot be similarly activated in normoxic tissues due to competing oxidative pathways (Nishida et al., 2008). Our results from HPLC analysis to determine whether CYP2S1 is able to turnover AQ4N to AQ4M and AQ4 indicate that CYP2S1 metabolizes AQ4N under anoxic conditions to AQ4M and AQ4. When compared with the control samples, where PBS was used instead of the CYP2S1, there was no conversion of AQ4N to AQ4M or AQ4-there was only a single peak (retention time: $12.572 \mathrm{~min}$ ) corresponding to the AQ4N (Fig. 4A). However, in the reactions that involved CYP2S1, three distinct peaks of AQ4N, AQ4M and AQ4 were observed indicating the turnover of prodrug AQ4N to the active cytotoxic product AQ4 through CYP2S1 under anoxic conditions (Fig. 4B). Next, we tested whether increasing concentration of CYP2S1 protein will lead to dose 
dependent increase in the rate of metabolism of AQ4N. Our results indicate that the increasing concentration of CYP2S1 leads to increased turnover of AQ4N (Fig. 5).

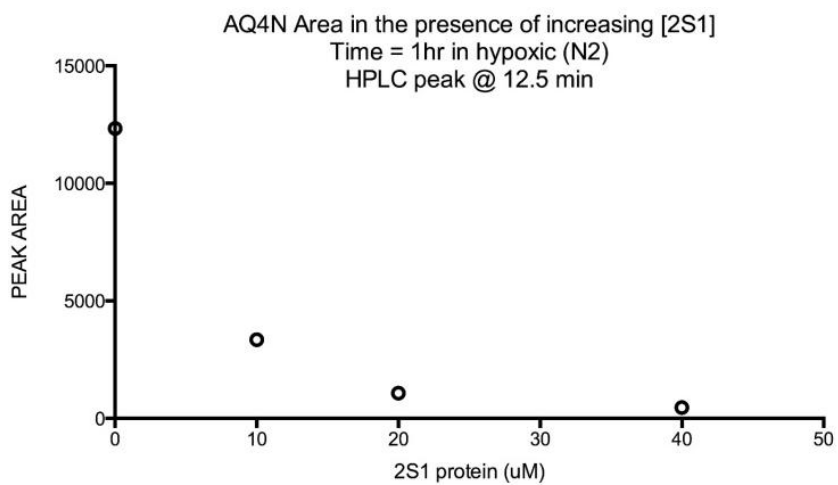

Fig. 5: HPLC analysis of bioreduction of AQ4N with increasing concentration of CYP2S1 under anoxic conditions. Increasing concentration of CYP2S1 lead to the increased turnover of $\mathrm{AQ} 4 \mathrm{~N}$ into $\mathrm{AQ} 4 \mathrm{M}$ and $\mathrm{AQ} 4$ and relative reduction in the peak area of AQ4N.

\section{Liarozole inhibits CYP2S1 and reduces the turnover of $A Q 4 N$ to AQ4M and AQ4.}

To understand more about the physiological function of CYP2S1 inhibition by liarozole, we treated microsomes from BEAS2B with liarozole followed by incubation with $\mathrm{P} 450$ reductase and NADPH under anoxic conditions. In our studies with CYP2S1 overexpressing microsomes, liarozole effectively inhibited the CYP2S1-mediated metabolism of AQ4N (Fig. 6). As can be seen in Fig. 6, In the presence of liarozole, CYP2S1 mediated metabolism of AQ4N to AQ4 is reduced, as is evident from the decreased turnover of AQ4N to its metabolites.

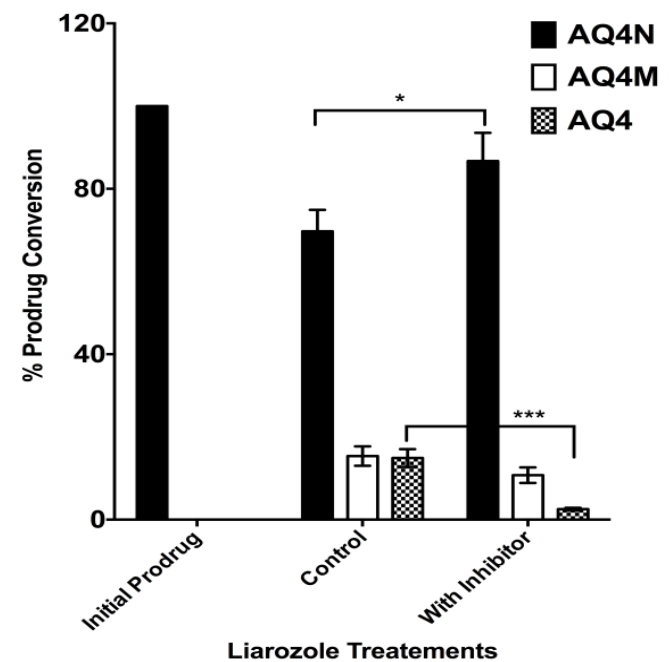

Fig. 6: CYP2S1 is inhibited by liarozole. Microsomes from BEAS2B were treated with liarozole followed by incubation with $\mathrm{P} 450$ reductase and NADPH under anoxic conditions. $10 \mu \mathrm{M}$ AQ4N was added and the reactions were incubated at room temperature for an hour followed by deproteinization. The supernatants were analyzed by HPLC for the conversation to AQ4M and AQ4 Liarozole was not added to the control samples. Liarozole inhibits CYP2S1 and prevents the binding of AQ4N to the enzyme, thus resulting in decreased turnover of $\mathrm{AQ} 4 \mathrm{~N}$ into $\mathrm{AQ} 4 \mathrm{M}$ and $\mathrm{AQ} 4$ when compared to untreated control samples. Statistical significance was determined using a Student's $t$ test. Data are represented as mean \pm S.D, ${ }^{* * *}, p \leq 0.001,{ }^{*}, p \leq 0.05$.

\section{CONCLUSIONS}

Cytochrome P450 metabolic studies play an important role in understanding the disposition and metabolism of various exogenous and endogenous metabolites. Identification of inhibitors for orphan CYPs is a useful tool in deducing their significance in the turnover of various substrates and also for effective enzyme studies. Our results indicate that liarozole is an effective inhibitor of CYP2S1, which has been tested against the substrate AQ4N. This study reveals part of the enzymatic role of CYP2S1 and ultimately its physiological role and significance in cancers.

\section{ACKNOWLEDGEMENTS}

We thank Dr. Charles B. Shuster (New Mexico State University) for providing access to Fluorescence microscopy, Dr. Aaron Rowland (NMSU) and Dr. Emily Scott (University of Kansas) for insightful discussions on CYP inhibition and Dr. William Norris (Western New Mexico University) for critical review of the manuscript.

\section{Financial support and sponsorship: Nil.}

Conflict of Interests: There are no conflicts of interest

\section{REFERENCES}

Nelson DR. Cytochrome P450 and the individuality of species. Arch Biochem Biophys 1999; 369:1-10.

Tang X, Chen S. Epigenetic Regulation of Cytochrome P450 Enzymes and Clinical Implication. Curr Drug Metab 2015; 16:86-96.

Szczesna-Skorupa E, Kemper B. Influence of protein-protein interactions on the cellular localization of cytochrome P450. Expert Opin Drug Metab Toxicol 2008; 4:123-36.

Nishida CR, Lee M, de Montellano PR. Efficient hypoxic activation of the anticancer agent AQ4N by CYP2S1 and CYP2W1. Mol Pharmacol 2010; 78:497-502.

Patterson LH, McKeown SR, Ruparelia K, Double JA, Bibby MC, Cole S, Stratford IJ. Enhancement of chemotherapy and radiotherapy of murine tumours by $\mathrm{AQ} 4 \mathrm{~N}$, a bioreductively activated anti-tumour agent. Br J Cancer 2000;82:1984-90.

Xiao Y, Shinkyo R, Guengerich FP. Cytochrome P450 2S1 is reduced by NADPH-cytochrome P450 reductase. Drug Metab Dispos 2011;39:944-6.

Frömel T, Kohlstedt K, Popp R, Yin X, Awwad K, BarbosaSicard E, Thomas AC, Lieberz R, Mayr M, Fleming I. Cytochrome P4502S1: a novel monocyte/macrophage fatty acid epoxygenase in human atherosclerotic plaques. Basic Res Cardiol 2013;108:319.

Loadman PM, Swaine DJ, Bibby MC, Welham KJ, Patterson LH. A preclinical pharmacokinetic study of the bioreductive drug AQ4N. Drug Metab Dispos 2001; 29:422-6.

Nishida CR, Ortiz de Montellano PR. Reductive hemedependent activation of the n-oxide prodrug $\mathrm{AQ} 4 \mathrm{~N}$ by nitric oxide synthase. J Med Chem 2008;51:5118-20.

Kovacs MS, Hocking DJ, Evans JW, Siim BG, Wouters BG, Brown JM. Cisplatin anti-tumour potentiation by tirapazamine results from a hypoxia-dependent cellular sensitization to cisplatin. Br J Cancer 1999; 80:1245-51.

Tomasz M. Mitomycin C: small, fast and deadly (but very selective). Chem Biol 1995;2:575-9.

Papadopoulou MV, Bloomer WD. NLCQ-1 (NSC 709257): exploiting hypoxia with a weak DNA-intercalating bioreductive drug. Clin Cancer Res 2003; 9:5714-20. 
Seow HA, Penketh PG, Shyam K, Rockwell S, Sartorelli AC. 1,2-Bis(methylsulfonyl)-1-(2-chloroethyl)-2-[[1-(4-

nitrophenyl)ethoxy]carbonyl]hydrazine: an anticancer agent targeting hypoxic cells. Proc Natl Acad Sci U S A 2005; 102:9282-7.

Patterson LH. Bioreductively activated antitumor N-oxides: the case of AQ4N, a unique approach to hypoxia-activated cancer chemotherapy. Drug Metab Rev 2002;34:581-92.

Lalani AS, Alters SE, Wong A, Albertella MR, Cleland JL, Henner WD. Selective tumor targeting by the hypoxia-activated prodrug AQ4N blocks tumor growth and metastasis in preclinical models of pancreatic cancer. Clin Cancer Res 2007;13:2216-25.

Patterson LH, Craven MR, Fisher GR, Teesdale-Spittle P. Aliphatic amine N-oxides of DNA binding agents as bioreductive drugs. Oncol Res 1994;6:533-8.

Van Wauwe J, Van Nyen G, Coene MC, Stoppie P, Cools W, Goossens J, Borghgraef P, Janssen PA. Liarozole, an inhibitor of retinoic acid metabolism, exerts retinoid-mimetic effects in vivo. J Pharmacol Exp Ther 1992;261:773-9.

Kang S, Duell EA, Kim KJ, Voorhees JJ. Liarozole inhibits human epidermal retinoic acid 4-hydroxylase activity and differentially augments human skin responses to retinoic acid and retinol in vivo. $\mathrm{J}$ Invest Dermatol 1996;107:183-7.
Smets G, Van Ginckel R, Daneels G, Moeremans M, Van Wauwe J, Coene MC, Ramaekers FC, Schalken JA, Borgers M, De Coster R. Liarozole, an antitumor drug, modulates cytokeratin expression in the Dunning AT-6sq prostatic carcinoma through in situ accumulation of alltrans-retinoic acid. Prostate 1995;27:129-40.

Nelson, C. H., Buttrick, B. R. \& Isoherranen, N. Therapeutic potential of the inhibition of the retinoic acid hydroxylases CYP26A1 and CYP26B1 by xenobiotics. Curr. Top. Med. Chem. 2013; 13:402-28.

Pavez Loriè, E., Chamcheu, J. C., Vahlquist, A. \& Törmä, H. Both all-trans retinoic acid and cytochrome P450 (CYP26) inhibitors affect the expression of vitamin A metabolizing enzymes and retinoid biomarkers in organotypic epidermis. Arch. Dermatol. Res. 2009; 301: 475-85.

\section{How to cite this article:}

Singh NKM, White SR, Kalagara S, Kadavakollu S. Inhibition of CYP2S1 mediated metabolism of anticancer prodrug AQ4N by liarozole. J App Pharm Sci, 2017; 7 (02): 001-007. 